\title{
Development of a Novel Military Veteran Academic Pathway Program in an Australian University: Transition and Identity Making in Higher Education for Student Veterans
}

\author{
Piper A. Bell ${ }^{1}$ \\ ${ }^{1}$ Flinders University, College of Humanities, Arts and Social Sciences, Sturt Road, Bedford Park South \\ Australia 5042 \\ Correspondence: Piper A. Bell, Flinders University, Bedford Park South Australia 5042. \\ Email: piper.bell@flinders.edu.au
}

Doi:10.23918/ijsses.v8i2p278

\begin{abstract}
In Australia, existing Australian Defence Force and Department of Veterans' Affairs transition programs largely focus on vocational training and reskilling, mental health, well-being, and physical rehabilitation. Higher education has historically not been well supported as a pathway for many transitioning veterans, yet it can in fact provide a pathway from service to civilian life that gives meaning, identity and a sense of belonging to a veteran's life and, critically, helps them develop a sense of individuality and self-efficacy - key features required for a 'successful' transition out of the structured constraints of military life. The Military Academic Pathway Program (MAPP) was piloted at Flinders University, South Australia in 2019 as an intensive four-week program that aimed to develop independent learning skills and prepare students for university study and culture. This paper reviews the MAPP, from design, implementation and post-delivery reflection, from the unique position of teacher-researcher using a naturalistic inquiry methodology and employing qualitative methods for data collection, including observation and semi-structured testimonial interviews, as well as academic results and admission rates. The findings present modest yet promising results for the merit of the novel program.
\end{abstract}

Keywords: Veterans, Pathway Program, Higher Education, Belonging, Veteran Transition, Researcher Positionality

\section{Introduction}

Separating from the military is a uniquely challenging experience. As veterans transition out of the rigid, authoritative, yet simultaneously secure, structure of military life, they can experience a sense of 'reverse culture shock' (Bergman, Burdett \& Greenberg, 2014) as they return to civil society. The transition process involves reorientating their sense of belonging, purpose and identity, whilst they are often coping with a

Received: May 14, 2021

Accepted: June 25, 2021

Bell, P.A. (2021). Development of a Novel Military Veteran Academic Pathway Program in an Australian University: Transition and Identity Making in Higher Education for Student Veterans. International Journal of Social Sciences \& Educational Studies, 8(2), 278-296. 
range of medical, social and psychological issues as a result of their service. In Australia specifically, veterans are at a higher risk of unemployment and underemployment. They also have an increased risk of mental illness including depression, anxiety, substance abuse, post-traumatic stress disorder, and somatic problems (Harvey et al., 2018).

The Australian Defence Force (ADF) and Department of Veterans' Affairs (DVA) recognise the complexity of the transition process for veterans and manage the process via specialised transition units with the aim of facilitating a 'seamless' transition and attempting to mitigate challenges where possible. There are extensive service providers supporting veterans with mental health and wellbeing programs (The Road Home, RSL DefenceCare, Prince's Trust Australia), counselling, rehabilitation, and complementary therapies (Mates4Mates, Australian National Veterans Art Museum's Arts programs), employment services (Step Up Program, Soldier On, StoryRight, WithYouWithMe), and advocacy support (Legacy). ADF and DVA transition programs have historically tended to prioritise these kinds of rehabilitation and vocational training over higher education. Yet, critically, higher education can be a highly beneficial and advantageous pathway that can provide meaning, identity, and a sense of belonging to a veteran's life.

In 2018, Harvey et al. identified that very few Australian universities recognise and respond to the explicit needs of veterans entering tertiary study, nor do they recognise the skills and qualities that veterans bring to their studies and university communities. Often the transition from a military culture, which is structured around beliefs of 'service, bravery and obedience', to university, where the focus is on 'education, intellect and questioning', can be challenging (Bichrest, 2013). Many United States studies highlight the need for welcoming, supportive, and targeted programs for veterans which include the establishment of accessible counselling and support services, facilitating links with fellow student veterans and specific transition processes (Borsari et al., 2017; Hanafin, 2012). The Military Academic Pathway Program (MAPP), an Australian first, responded directly to these observations. The MAPP pilot was launched in 2019 at Flinders University, South Australia funded through the Department of Veterans' Affairs' 'Supporting Younger Veterans' grant in partnership with the William Kibby VC Shed. As a researcher on this project, and in collaboration with the University, I developed, coordinated, and taught the pilot as a free, fourweek intensive program, specifically designed to assist military personnel transition successfully into higher education by introducing them to university study through academic and social skills development, campus tours, facilitated engagement with support services, linking with peer mentors and academic advocacy. Successful completion of the program enabled students to be admitted to a range of undergraduate degrees at Flinders University.

In this paper, I explore higher education as a positive and meaningful transition pathway for veterans and examine the MAPP through post-delivery reflection from the unique position of teacher-researcher. I employ a naturalistic inquiry methodology using observational data, examine semi-structured testimonial interviews as well as academic results and admission rates to consider the results, efficacy, and success of the novel program. 


\section{Literature Review}

\subsection{The Transitioning Military Veteran}

Before outlining the experience of transition from military service to civilian life, it is important to identify a definition of 'veteran'. Noting that there is no universal definition of 'veteran', for the purposes of this paper, and in accordance with Australian policy following the United Kingdom's definition, the term 'veteran' refers to all ex-service personnel and includes anyone who has served in uniform for at least one day in the Australian Defence Force (ADF) (Ashcroft, 2014). Within the military, three broad groups can be identified across the Air Force, Army and Navy. These include commissioned officers (CO), senior non-commissioned officers (NCO) and 'other' ranks. These differences are important to note as ranks present nuances in the transition out of service for veterans, specifically in relation to educational attainment.

Approximately 6,000 service personnel discharge from the Australian Defence Force each year and return to civilian life. The majority of discharging personal have served in the Army, are in their mid-20s, and have served for approximately eight years. Approximately $18 \%$ of members leave due to medical reasons (Productivity Commission Report, 2019). Other reasons for separation include failure to complete initial training, redundancy, reaching compulsory retirement age, and disciplinary actions (Commonwealth of Australia, 2017).

The change involved with the transition out of military service and into civilian life can involve a range of difficulties, as documented by international research, including social isolation, family stress and violence, substance abuse and mental health issues, as well as challenges with employment, education, general health, and personal beliefs and identity (Albertson 2019; Black \& Papile, 2010; Bichrest, 2013; Livingston et al., 2011). Specifically, in Australia, veterans are at a higher risk of unemployment, underemployment, or employment in unskilled labour positions (WithYouWithMe Veteran Employment Report, 2017, cited in Harvey et al. 2018). Veterans also have an increased risk of mental illness including depression, anxiety, substance abuse, post-traumatic stress disorder, and somatic problems (DVA, 2017). Furthermore, men between the ages of 18 and 24 are at twice the national average of being at risk of suicide (Australian Institute of Health and Welfare, 2017, cited in Harvey et al. 2018).

The 2019 Productivity Commission Inquiry Report, A Better Way to Support Veterans, presents a moderate understanding of these issues, stating that most veterans in fact make a 'relatively smooth and successful transition to civilian life' (Productivity Commission, 2019, p. 49), yet acknowledges that 'some' do experience difficulties and 'stress'. Whilst likening the transition for veterans to other professions such as professional sport or opera singing due to their being more than simply an occupation but a 'way of life' (p. 302), it is also acknowledged as a stage of grief and 'sense' of loss in separation, including the loss of military culture and community, of identity and of purpose (Romaniuk and Kidd 2018, cited in Productivity Commission 2019, p. 302). The report identifies, then, that a failure to acknowledge this within transition services who refer to, or aim for, an ideal 'seamless transition' do a disservice to veterans (p. 287). Thus, there is a real need for effective transition support services. 
Currently, to assist with separation and transition, the ADF offer a range of programs and services to better support veterans and their families during the return to civilian life. Younger veterans, particularly those serving in lower ranks with skills that are not easily acknowledged or transferred into the civilian labour market, are more likely to be at risk during transition. And, until recently, services specifically aligned to their needs did not exist or were difficult to find and access, particularly for vulnerable people. In response to this, the Productivity Commission made the recommendation, relevant to this field, that the ADF should establish a 'package of transition support', which includes enhanced services and support to gain skills and qualifications post-service by 'trialling an education allowance for veterans undertaking full-time education or vocational training' (Productivity Commission, 2019, p. 283). In doing so, the Productivity Commission notes that Australia can profit socially and economically by providing better support, particularly for those injured or affected by illness. Specifically, better skilled veterans will reduce future reliance on taxpayer funded support (Productivity Commission, 2019, p. 339).

\subsection{Education and Identity-Making}

Higher education can be a meaningful pathway for military veterans returning to civilian life. For all students, higher education provides improved future employment prospects, increases life purpose, builds social confidence, develops social connections, and improves wellbeing (Daly et al., 2015; Bauldry, 2014; Schlissel, Schill \& Drake, 2018). Veteran students hold a 'non-traditional' student profile, being typically older, financially independent, and often having family responsibilities (Ford \& Vignare, 2015), thus, it is argued, require additional support for success in higher education. Non-traditional students, generally, have lower completion rates and higher attrition (Taniguchi \& Kaufman, 2005) and have lower grades than traditional students (Brändle \& Lengfeld, 2017). Further, veteran students are also more likely to have mental health and physical challenges post-service than the general student population (Kazis et al., 1998). Importantly, whilst these challenges may increase veterans' difficulties to complete higher education, their identified strengths may indeed mitigate them (Cate, 2014). In fact, military veterans have the capacity to be 'ideal' students because of their diverse life experiences, motivation, discipline, timemanagement, goal setting and team-work skills, self-efficacy, persistence, and resilience (Harvey et al., 2018).

Until recently, very few Australian universities recognised and responded to the explicit needs of veterans entering higher education (Harvey et al., 2018). Australian universities have tended to focus on Recognition of Prior Learning (RPL) in meeting entry requirements based on service (e.g., Griffith University) or rank (e.g., Charles Sturt University) or to encourage participation and engagement in academic studies with the institution broadly (e.g., University of South Australia's Invictus Pathway Program). The Australian Catholic University's Student Veterans Support Program (SVSP) initiated more tailored and substantive support by way of negotiating study arrangements and academic adjustments, access to early timetabling, intermission after one semester, and disability 'Access Plans' as necessary.

However, Australian universities are now starting to recognise the specific needs of their current and prospective veteran students by presenting themselves as 'veteran friendly' (Harvey et al. 2018). The Australian Student Veteran Association, a national student association with chapters across Australian universities, has also assisted with connecting veterans to universities and providing advocacy support for veteran transition to higher education. The MAPP, specifically, set a new tone in the Australian university 
context for engaging veterans in higher education through a targeted pathway program, accompanied by the development of a veteran-specific mentoring program and student association, two important strategies designed to assist veteran students' transition to university life.

\section{Methodology}

This paper uses qualitative research design strategies to enable an appropriate level of depth in collection, description, and analysis of data (Denzin \& Lincoln, 2005). This paper embraces a naturalistic and interpretive approach, which enabled flexibility in capturing the experience of teaching and learning in a context that was natural and non-manipulated (Patton \& Patton, 2002; Baumfield et al., 2008), as well as creating research aims in the midst of observational data collection and interpretation of results. The responsive design of this research was necessary to facilitate the effective capture of teacher and student experiences of the program (Ormston et al. 2014). In essence, this research involved exploring phenomena 'from the interior' (Flick, 2009), which, for this paper, has emerged through the use of interview and observational data from the classroom environment.

Data have been collected and reviewed through field notes and testimonial interview transcripts. Themes were identified from the data and naturalistic interpretations have been made in 'making sense of' and developing explanations of these themes sociologically. In this way they work 'inductively, from the ground up, and eventually develop location-specific theories or accounts based on analysis of primary data' (Armstrong, 2012). Of course, it is essential that researchers tackle issues of subjectivity by selfreflecting and self-critiquing (Walker, 2012, p. 78). So, for instance, as an experienced university lecturer, I was familiar with the content of bridging and transitionary programs, however, as the researcher, I was actively aware that the veteran student experience, both as a student and subject, was unfamiliar and, indeed, unique. This inherent consciousness ensured a level of reliability, reflexivity and understanding of my positionality ensuring maintenance of the 'researcher' role in observational data collection, whilst doing the job at hand (Blaikie, 2009). In addition, some triangulation has been employed through the use of incidental documents generated as part of the teaching process, and through the use of brief interviews.

\subsection{Methods}

For the purposes of this paper, several methods of data collection have been employed due, in part, to my positionality as the researcher, and in part due to the necessity of evaluating my own teaching in a novel context. First, organisational data have been collated from participant completions of the MAPP and commencements into undergraduate degrees at Flinders University ${ }^{1}$. Second, observational data from the field, complemented by testimonial interview data, will be presented to provide a deeper level of analysis.

Participant observations were made throughout the four-week program. Observations were made from the position of teacher, the participants being the students. Observed activities included the students as passive learners (e.g., during lectures or content delivery), as active learners (e.g., in class activities, individual work or group work), and outside of class where possible (e.g., how the students spent their lunch breaks).

\footnotetext{
${ }^{1}$ Noting that some participants may have enrolled at alternative institutions post-program. It is important to note that students' successful completion of the MAPP enabled them entry into a range of courses at Flinders University, however this was not transferable to other universities.
} 
Observational data was recorded in field notes in unstructured descriptive notes and subjective reflections that provide more context, depth and analysis to the interview data.

During the final week semi-structured testimonial interviews with eight students were conducted by a Research Assistant. These were captured in audio-visual format for the 'Vets at Uni' public website (now defunct). Students were asked to reflect on their experience in the program, as well as in relation to their transition from military service to civilian life, specifically in relation to whether they saw higher education as a suitable option for themselves. The students volunteered (and consented to media release) to have these interviews 'released' publicly, and the data were made available in the form of YouTube video recordings on the project website. Students were asked several open-ended questions relating to their military service background, their reasons for entering into the MAPP, their experiences completing the program, and whether they would recommend it to another veteran.

For this paper, all students have been anonymised in order to protect their confidentiality. Thematic analysis was used to analyse the transcribed interview data, by identifying patterns and developing key themes in line with the research objectives (Spencer et al., 2014).

\section{The Military Academic Pathway Program}

The MAPP was designed as a four-week intensive program with the purpose of assisting military veterans to transition successfully into university, both academically and socially. The program aimed to develop practical academic skills, interpersonal skills, and improve self-confidence. The program's aims were to develop students' skills in: academic writing, argumentation and critical thinking; effective research strategies and using the library; correctly referencing their work; appreciating diversity and alternative perspectives; critically reading and comprehension of a range of texts; communicating their ideas on a given topic orally and in writing in a clear and logical manner; a basic understanding of statistics and how to interpret and evaluate statistical data; and, using computing programs and online learning tools to an appropriate standard.

In developing the MAPP, I reflected on my teaching (and learning) experiences and drew on international research, as well as seeking feedback and consultation from students and key networks. I spoke with current student veterans (in particular those who had previously completed the University's mainstream preparatory program), staff from the Department of Veterans' Affairs, Transition Office staff, and sought advice from the national Australian Student Veterans Association. Based on this consultation, considerations were made for class times, dates, content, and areas for learning outcomes which focused on veterans' needs. I also collaborated with staff across the University, working with the Student Learning Support Service to develop the academic literacy and numeracy curriculum and inviting staff from Careers, the Library, Health, Counselling and Disability, and Flinders' central Student Association to hold workshops, as well as members from the 'Vets at Uni' research team. I also connected with academics across the University to bring diverse academic voices and perspectives in teaching this cohort, introducing students to different discipline areas in the process. 


\subsection{Eligibility}

Applicants for the MAPP were considered for enrolment based on evidence of service history and previous qualifications and a written personal statement. Applicants were required to provide evidence of their position held and years of experience and details of previous education and training. This was gathered in the form of their Record of Service. Students participated in a one-day workshop facilitated by 'StoryRight' prior to the formal commencement of the MAPP. In this workshop, participants produced a short personal statement that captured their existing skills and goals relating to tertiary study.

\subsection{Admission to Flinders University}

Students were considered for admission to an undergraduate degree based on the three parts of the portfolio, including successful completion of, and academic results, in the MAPP, written statement and evidence of prior service and skills. Assessment of participants' applications were completed using appropriate measures by the University's Student Recruitment Office in consultation with me, as the Program Coordinator, in relation to academic performance and perceived 'readiness' for university study.

\subsection{Participant Demographics}

26 students enrolled into the program, the majority of which were male (23), aged under 30 (16), and from English speaking backgrounds. Of the students, 12 held a Certificate III, or higher level, qualification, with three holding Diplomas, Bachelor or master's degrees. In most instances, qualifications were completed within, and related to, military service (e.g. 'Certificate X in Military Studies'). Eight students did not hold a Certificate II level qualification. The majority of participants were still actively involved in military service (16), with most specifying that university was part of their future transition 'plan' upon separation from service.

\section{Results}

\subsection{Demographic Data: Academic Performance and Conversion}

Of the 26 participants, 19 successfully completed. Of the unsuccessful participants, four withdrew for reasons unrelated to the program, such as being relocated, being discharged interstate, and gaining interstate employment, thus affecting their ability to physically attend classes. Each of the withdrawals provided positive feedback of their experience in the program. Three participants did not successfully pass the program: two due to failure to submit the final essay, and one due to a self-selection to undertake the University's general, and extended, bridging program prior to commencing an undergraduate degree.

Of the 19 successful completions, 53\% accepted an initial offer made by the University, with 50\% of students enrolling in Semester 1, 2020. Importantly, some students were delayed in commencing studies due to discharge and military commitments. Additionally, many MAPP students were not in the process of official separation from service, but rather exploring their options for future transition. In some instances, students planned to commence part time or online study to accommodate service commitments prior to discharge. Only nine of the students were discharged or considered 'in transition' at the time of the program ( 3 reservists, 4 retired, and 2 transitioning) with the majority, 16, still in active service. The 
conversion data indicates that active status may have proved difficult for enrolling in study whilst still serving. Further, of the 'ready' students, some indicated during the program that they did not wish to pursue university education, regardless of enjoyment of the MAPP, and others selected alternate universities. The COVID-19 global health crisis also presented a further complication for prospective and current - students in 2020 specifically (Cornelius-Bell \& Bell, 2021). For veterans, COVID-19 may have further delayed or complicated their discharge, or the notion of studying online during the pandemic may not have appealed to them.

While this data provides some statistical insights into conversion, the qualitative data provides a deeper look at the student experience in relation to perceived preparedness, improvements in confidence, selfbelief, and senses of belonging.

\subsection{Observations}

\subsubsection{Ideal Students}

As expected, the students were engaged with the coursework, demonstrated exceptional work ethic, dedication, and commitment to their own success throughout the program. They attended on time for classes, came prepared with laptops, notebooks, food, and the provided resources (e.g., program guides, readings etc.). They listened to all content delivered with intent, maintaining eye contact, and were noticeably not distracted by, for instance, phones or conversations with colleagues, as commonly seen with 'normal' university students. They asked questions confidently and respectfully as needed, using confirmation-structured questions (i.e., 'you said x, does this mean y'). They absorbed information quickly, demonstrated good recall abilities, took detailed notes in all sessions, utilised available resources (including study guides), and demonstrated a genuine interest in their studies and intellectual growth. Again, this was a marked difference from common university students, who often take time to adjust to the idea of independent study and responsibility, or onus, of their work and understandings of course content and requirements. Students also engaged well with other lecturers and university staff, asking questions, and discussing the content clearly in later tutorials. This is, of course, in line with Harvey et al.'s (2018) findings that veterans hold many of the strengths that predict university success, including a highly developed work ethic, goal-setting skills, self-efficacy, persistence, discipline, resilience, time management, and teamwork experience.

\subsubsection{Social Groups and Rank Effects}

There were clear divisions amongst the class: those that perceived themselves as more mature and earnest about study, as well as the two Navy personnel; older male students; younger students discharged and ready to commence study; and, younger, still serving, students from the same Unit. That some were still serving did affect interactions amongst students. For instance, in the first week of the program two students (still serving) approached me to raise that they felt they could not contribute to class discussions as freely as they would like due to a Lieutenant (still serving) being present. This person was not their direct superior, but they felt they were unable to speak openly with their presence felt. On the other side, the Lieutenant had also enforced salutes and to observe appropriate military address with these students. Older (discharged) students, and those of higher ranks, raised with me frustration when they felt that the younger 
(serving) students were 'misbehaving' in class. This was, actually, a learning opportunity for the older students, as the perceived behaviour was unproblematic and some social interaction in the classroom is good for engagement, morale, and thus learning.

\subsubsection{On Having Military Culture Challenged}

One notable workshop caused controversy and strong emotional responses from the students. The presenter, an academic who researches militarisation, came to speak to the group about their own personal experience in the Army and transition out of military service. The intention of this session was to help students to understand 'acceptable' behaviour and communication at university using a voice that had an experiential understanding of the students' backgrounds. As part of the session, the presenter introduced the students to their research which explores institutional abuse in the military, the sexism within it, and asked for their input based on their own experiences. Students were quickly and visibly rattled by what they felt were assumptions about their plight (e.g., the women's experiences) and about the current conditions in the military (e.g., younger students felt some of the critiques of the organisation were outdated). The students did attempt to debate and discuss the content with the presenter, and I indeed attempted to remind them of the skills we had been developing in critical and logical reasoning in argumentation and analysis, however the feeling of frustration and defensiveness in the room was palpable (in some, faces were visibly red with heat and anger). Students accused the presenter of being too far removed from active service, from a lack of exposure to combat, and a limited understanding of being a female person in the military. Thus, rather than students learning how to appropriately communicate in an academic setting, they were provoked and offended.

After a break, I delayed the planned session and decided to spend time reflecting and supporting the students to critique rather than censure through some guided discussion. This enabled the female students to speak about the issues they had with outsider research pressuring and influencing internal strategies toward gender equality in the military. As examples, they discussed special women's morning teas and flirty pop songs singing about respect for women in the ADF (see 'Sisters in Arms', 2018). They discussed the harm this does to them by segregating them as the 'other' through strategies that were designed to help them. The younger, serving soldiers spoke about the purpose of the military and how the presenter had outdated or limited perspectives.

Not all students were upset from the session, however they collectively felt that they were attending the MAPP to transition into university, rather than to critique their service. One student stated that 'any military related content should be avoided as people are attending this course to get away from Defence life and culture'. Indeed, the MAPP was a program for veterans, rather than a program about them. Whilst the program recognised the challenges of veterans and assisted with their transition, the focus was to assimilate them to university as opposed to enhance their sense of isolation in highlighting their complex histories. In relation to advancing their communication skills in workshop settings at university, this was most effectively achieved via the implicit 'training' through tutorial discussions on abstract ethical and political issues that helped them to develop their critical thinking, reasoning and argumentation skills as required for academic study and collaboration with others. 


\subsubsection{On the Perceived 'Normal' University Student}

When students were asked about their perception of the 'normal' university student, they described them as lazy, 'vegan', weak, inexperienced, and having limited understanding of the 'real' world. They used the example of the University's Academic Integrity Policy terminology being changed from 'Academic Integrity Breach' to 'Academic Integrity Issue' as a way to joke about the sensitive nature of university students. They thought it humorous that I would be surprised and appreciative of their studious nature, for instance in diligently completing readings, being on time for classes, and their composure on presentation day, laughing at my reminding them (in an autopilot way) to 'be on time tomorrow'. They were critical of the implication that 'normal' university students in fact needed these kinds of reminders and reinforcements. They were also openly frustrated when the younger students were beginning to arrive slightly late or would become off-task in class activities. This perceived and created sense of difference and separation may have been related to a lack of confidence and feelings of wanting to maintain a sense of existing identity and self-esteem.

Over the four weeks, there was a small observed shift in which they felt more comfortable in their student identity and were more respectful and appreciative of the mainstream university students who they had started to interact with. Interestingly, though, there was a marked difference between the students that were going to - indeed, ready to - enter undergraduate study immediately upon completion of the program (with limited separation from the perceived 'other'), those that had decided not to take on study (moderate separation from the perceived 'other'), and those that were still serving (strong separation from the perceived 'other'). Worth noting here is the role that the veteran's student association played and contributed to perpetuating a distance between military and non-military students. This kind of veteranspecific student association, although highly engaging and positive for some veterans, had started to reinforce hierarchical structures, within what is essentially a student social club, such as different club shirts based on 'rank' by way of year level in degree. Thus, my intention for a mentoring program was in fact to avoid possible segregation by linking new veteran students to current veteran students that were not members of the association. My aim was to connect students to those that understood the lived experience of transitioning from military service to provide meaningful peer mentoring support, but who were engaged in the University as individuals in their study, identifying themselves as students rather than veteran students necessarily.

\subsubsection{A Clear Shift from the Veteran to the Student}

Perhaps one of the most important observations, relative to the intention of the program, came in the way of students' social conversations shifting from discussing the commonality of military service to 'study talk'. These conversations started to be present in place of other daily, mundane exchanges (e.g., waiting for classes to start, during breaks etc.). For instance, on the topic of 'what did you get up to last night?', started to be focused on what study was done last night, or asking one another if they found the readings difficult, or what classes they were looking forward to that day. In their lunch breaks they told anecdotes that involved imagining themselves on campus together the following year, playing games in the university tavern and envisioning themselves staying up late writing essays. The unconscious shift in discourse from ranks, service histories and combat stories, to research, tackling abstract ideas long after the associated tutorial, and concern to meet assessment deadlines, was the key indicator that the program succeeded at 
assisting with the transition to university for veterans. Even the seeming 'misbehaviour' from students (e.g., arriving late to a class) marked signs of independence and a freedom from ranks and the constraints of military management structure. This worked in two ways: being late, for example, demonstrated an awareness of knowing that they would not be reprimanded for a late attendance, but also highlighted the fact that they were voluntarily opting into the experience and developing a value for their education in the process, because they did, of course, attend after all.

\subsection{Testimonial Interviews}

All students expressed that they enjoyed the program, felt more confident about their ability to complete academic study, further emphasising what has been established in the previous section. However, the testimonial interviews, which took place at the end of the program, also highlighted that the students felt the program, and university study more broadly, was a suitable, valuable, and meaningful pathway for veterans. As they reflected on the program itself, they frequently cited it in relation to assisting them with the transition. This was particularly evident for those from lower ranks. Students not only indicated that higher education provided them with a shift in responsibility and purpose, but they also identified their military skills as transferable to academic study.

My background in the military was four years in the infantry corp. I served three years in second battalion and one year in the seventh... I enrolled in the MAPP because I was interested in pursuing a university degree, and I definitely need assistance transitioning from the military lifestyle to one of academia... So far, the MAP program's been fantastic. It's allowed me to understand what is required in an academic environment, and has also allowed me to transition a lot of my military skills and a lot of the values that I have into a more academic role...

The most challenging thing about the MAP program is definitely the transition from military environment into an academic one. But with the assistance provided by the staff at Flinders University, it's made a lot easier than if it's done on your own... [they] assist people who are struggling with the transition from military to civilian [life].

I would hundred percent recommend the MAP program for anybody who's currently serving or previously served military who's looking to transition into an academic role. It provides all the resources you need and all the tools to bridge your military skills into an academic role. (Student 1).

Students that previously had not seen themselves as academically minded also expressed a sense that higher education was a viable option that, again, would build on their military training.

So, I spent 8 years within Defence as a transport driver. But within the last two years have suffered a major accident where I was crushed between two cars. So, I've had to rethink my life and have to change my career path because I can no longer do physical activities... I found the MAP course very useful for someone that was never an educational guy. Like I left school as soon as I could work full time. I got my passing grade to join the military, 
joined the military, and came in. I've learnt a lot of good basics and I think I should be able to establish a good Uni life. (Student 2).

The most valuable thing is actually realising that I can do Uni. I always thought that was something that was well out of my league. But actually, since attending this course, it's only realised that it is something that is achievable, most definitely. (Student 5).

There's obviously this stigma saying that, you know, if you're in the Army you should, like, you know, be quite dumb, you shouldn't go to Uni, but I haven't found that the case. Everybody is quite intelligent, and I am extremely fulfilled doing this course. And it's opened my eyes to help me realise that, you know, university, anyone can do it, and especially from the military, you got some soft skills that will help you do that. (Student 7).

It's challenging because I've been out of school for over a decade. I've done apprenticeships and studied a little bit, but not at the level of university. Not at the high academic level. So, it's challenging, but it's actually supportive as well. There's plenty, plenty of support in the program, which is good... You know, you go to work for so long that you sort of lose a lot of those study skills, developing study skills, and try to pick up information from reading, rather than just like reading for fun. You got to actually yeah critically read, which is not a skill that I am strong in, but yeah, there's plenty of coaching there to get you better at it. So it's good. (Student 6).

Students also identified the radical change between the structure of military training and the higher education teaching approach and learning environment.

It's just the structure and the lifestyle of Uni, I think really helps, especially from military to civilian, the difference is huge. And the way Piper describes it all is really good and she doesn't degrade you at all. Like when she's giving the lessons you feel like you can be involved and she's not looking down on you. (Student 2).

It's still the lifestyle change is huge, like just meeting people around the campus saying good morning to them. They're just not used to that sort of things like within the military. You always say good morning to someone. You always have the structure there. Like, with Uni it's a lot more relaxed and a lot more different people. So, it's more just that the cultural change. (Student 2).

.. being the different environment, I think, for me, because I come from such a structured work environment. So just being able to rock up in whatever you want and stuff, but it's been pretty, not hard but like, been a bit different. I guess not so much as challenging, just a bit different. (Student 4).

It's a drastic change in difference from being told what to do every day, where to be, how to do things, which suits a lot of us separately, whereas this is very much going back out onto your own. Learning individualistic things and having to do things by yourself and not 
working as a team has been a massive difference. It's a challenge but it's something that definitely is very suited to us. (Student 5).

The experience was similar for older students who were experiencing the foreign nature of academic work after a long period of service. However, they were able to reflect on how well they felt they had done after completion of the program.

I was a long-term soldier in the Defence Force. I did about 38 years. I finished a couple of years ago and after a gap year, I decided that I needed to get my brain stimulated again.

The first few days [in the program], it was a bit of a struggle getting used to learning and was a little bit of a struggle. But Piper made me feel very comfortable and very safe. And as that, as it went on, my skills picked up rapidly and I found it very good.

My writing skills, most definitely [have improved], I've been able to go from a military type writing to now a university type writing and I found that quite good... I have a certain amount of reading to do. I have a different way of, of speaking. I have to put things in argumentative form rather than just emotional form. There were a few challenges, but you know, four weeks, I think we've got it! It's not just one of those 'read, get out' type things, [the staff are] always available after hours for you to come and have a talk to. They're quite happy to proofread your work and that's what this course is all about. (Student 3)

Students identified that studying alongside other Defence personnel assisted them to feel comfortable in the new learning environment:

I joined the Navy in 2008 as a marine technician, and then I transferred to the Army in 2016 as an electrical technician... so I've spent 11 years in Defence... I am getting medically discharged from Defence, and ... this course came up as an introduction to Uni. And it was great because of [it being with] a group of other Defence personnel, and so I feel comfortable sort of coming on and giving it a crack.

[it has been] really informative like considering I haven't been in school for 12 years now. It's been great to sort of start from the basics and start to get our heads wrapped around writing essays and structure and that sort of stuff. (Student 4)

It's actually been one of the best courses I've ever done. Just by the likes of it engages you and in having people that have been in ... Defence. It's helped with the understanding of the course and how we operate as people because we sort of think outside the norm and differently, and it's allowed us to be able to weld into the University of life and actually get the most out of it. (Student 5)

Finally, students identified a new sense of purpose in light of limited prospects post-service.

Unfortunately, due to my injury I can't continue on with the Defence Force. I can't get back to being a tradesman like I used to, so now I'm looking at a future where I can do something 
that's not quite as physical, but I can still use my brain and actually not sit there and do nothing. (Student 5).

I think it's a program that has actually given us everything we've needed to be successful. (Student 8).

I highly recommend that even if they're not choosing Uni, just to the fact that it opens up so much more opportunities for yourself, developing yourself, like you're improving yourself, essentially, like, there's no harm in doing that, especially if this course is provided for veterans. I strongly suggest it because you never know where you're going to be afterwards. (Student 2).

\section{Discussion}

University can provide a meaningful pathway for veterans returning to civilian life in providing a platform to re-establish and redefine one's identity, sense of purpose and belonging. Higher education provides improved future employment prospects, increases life purpose, builds social confidence, and develops social connections. Veterans have the capacity to be 'ideal' students because of their diverse life experiences, motivation, discipline, time-management, goal setting and team-work skills, self-efficacy, persistence, and resilience. The MAPP results demonstrate that veterans hold the personal attributes that enable them to develop the necessary academic skills required to perform well academically (e.g., diligence, motivated approach and value toward learning, resilience, etc.). However, veteran students are also at risk of experiencing difficulties and challenges at university (Harvey et al., 2018). Their unique attributes both work to their advantage and disadvantage. On one hand, they are incredibly studious and capable which enhances their learning and advances their academic success. On the other hand, their unavoidable attachment to military culture (e.g., the examples provided in results which identified their perceived difference and separation from the 'other') may prevent them from assimilation to university culture, and therefore an authentic and meaningful transition. Critically, 'militarisation' has lasting effects and veterans must as a result redefine what they do as well as who they are (Jones, 2013). Thus, veteran students require appropriate supports to assist with their journey and develop their senses of identity, purpose and belonging in the university context. In addition to the importance of a 'veteran friendly' campus, as asserted by Harvey et al. (2018), pragmatic and meaningful approaches are needed, including strategic frameworks, unique enabling programs, and tailored peer mentoring services.

There is a broad body of research literature exploring commencing students' transition into university (Lizzio, 2006, 2012; Araujo, 2014; Nelson et al. 2012; Thomas, 2012; Tinto, 2009; Meehan \& Howells, 2019). Lizzio (2006) provides a widely used framework for commencing students' needs, satisfaction, engagement and persistence in higher education that ought to be considered when designing effective orientation and transition strategies in universities. Lizzio claims that a student's 'five senses of success' include a sense of capability, connectedness, purpose, resourcefulness and, at the centre, a sense of academic culture and clear values (2006). It is evident how these are critical for all commencing students; however it should also be clear that for military veterans specifically, this a familiar framework of socialisation that leads to success. By strengthening commencing students' sense of purpose through appropriate interventions and support systems, students are more likely to succeed at university (Lizzio \& 
Wilson, 2010). Further, Araujo et al. (2014) describe the transition into higher education as a process rather than as a single or isolated 'event'. Araujo et al.'s (2014) three-tiered model captures the student lifecycle as 'being, becoming and belonging'. Meehan and Howells (2019) identify the three things that 'matter' for students as 'the academic staff they work with, the nature of their academic study and the feeling of belonging'. They highlight the interconnected relationships between important psychological and social senses of purpose and belonging. For instance, learning enhances confidence in capability, capability enhances a sense of belonging, and 'belonging is linked to the psychological and sociological aspects of the students and where they feel a sense of purpose' (Thomas, 2012). In order to support transitioning students, universities must therefore recognise student diversity and 'mediate the transition through academic, social and support structures' (Nelson \& Kift, 2005, cited in Meehan \& Howells, 2019). Importantly, although veterans may share common issues reclaiming purpose, identity, belonging, as well as potentially holding a range of psychological, social and physical health issues, there are important differences between veterans and 'we cannot simply lump together different types of individuals with a connection to the military' (Molina \& Morse, 2015). Thus, it is necessary to recognise this as a diverse rather than homogenous group by way of their association to military alone, for they differ in relation to service history and between reservists, active duty and discharged personnel. They are further diversified in relation to income, family obligations, online accessibility, and so on (Molina \& Morse, 2015). Thus, in some ways, mainstream approaches to student engagement, particularly for engaging 'non-traditional' student profiles, are most appropriate, viable and useful.

Enabling and preparatory programs, generally, even short models, are successful for commencing students. They generally tend to attract students from non-traditional profiles, including those from lower socio-economic backgrounds, mature aged, first in family, and those with low admission scores, and have demonstrated impact on performance and retention. Research shows that students that complete preparatory programs are less likely to fail and will achieve higher grade point averages (GPAs) at the end of the first semester of study than those who do not complete a program that teaches important aspects of tertiary study such as university culture, critical thinking, teamwork, academic writing, and so on (McIntyre et al., 2012). Enabling programs can, in fact, be a leveller in relation to traditional entry pathways (for instance, year 12 graduates with high or sufficient Tertiary Admission Rank scores) and non-traditional student entry pathways. Chesters et al.'s (2018) research shows that tertiary preparation programs indeed provide viable alternative pathways into higher education. They can also be linked to similar levels of retention and completion of undergraduate degree as the traditional pathway through an early immersion in university culture and provisions of support in relation to learning. The MAPP's success in building students' confidence was of course, at least in part, due to the provisions of supportive learning in this way. Teaching involved imparting critical content about academic research and writing and basic numeracy in an engaging, inclusive, and supportive way. Teaching also involved a level of nurturing and support to build students' confidence as individual thinkers and questioners with agency, which assisted them to transition from the constraints of staunch military culture.

An important final note is needed in relation to veteran support at university. Not only do veteran students experience challenges in their transition to university, Livingston et al.'s (2011) research shows that veteran students also often 'downplay' or hide their military association within the university campus context, are less likely to seek academic support, and are 'more inclined to pursue social support in the 
form of associating with fellow veterans with whom they felt more comfortable'. Thus, peer mentoring is a valuable approach to employ in engaging and supporting veteran students. As with enabling and preparatory programs, additional support by way of peer mentoring programs have become increasingly employed across Australian universities to help with retention and student success. In fact, 'peer mentoring is often considered the single most effective strategy for increasing student retention and student satisfaction' (Egege \& Kutieleh, 2015). Peer mentoring programs, whereby third year students provide mentoring for first year students, are demonstrated to enhance the five aspects associated with university success as identified by Lizzio (2006), as well as encourage deep and strategic learning approaches (Chester et al. 2013). In their research with first year psychology students, and designing a peer mentoring program using Lizzio's framework, Chester et al. (2013) found significant positive change on three of the five aspects of student success, with an increase in deep and strategic learning approaches, as opposed to superficial learning, of key content learning areas. As such, the MAPP was complemented with a peer mentoring program, the 'Military Mentors' program, tailored specifically to veteran students. While this was an important supplement to the MAPP and is worth noting here, it has not been the central focus of this particular paper.

\section{Conclusion}

The MAPP pilot was an innovative and leading higher education pathway program. The program helped to mitigate the barriers to higher education for veterans, with particular emphasis for lower ranks transitioning from a career in arms corps. The program attracted and welcomed the participation of veterans into tertiary education that will continue to contribute to their identity, purpose and belonging in life after military through greater access to employment, intellectual growth, self-efficacy, and independence in civilian life. In order to improve academic success rates, and thus appropriately support veterans with their transition from military to civilian, and student, life, a 'veteran friendly' campus is important to bridge the unknown between both parties. This can be achieved by providing a veteranspecific pathway program such as the MAPP, supplemented with a tailored peer-mentoring program. Importantly, not only is inviting veterans to explore higher education empowering for them emotionally and intellectually, but they also hold the skills and capabilities of an 'ideal' student that universities should actively seek out.

\section{Acknowledgements}

The Military Academic Pathway Program was supported by the 'Supporting Younger Veterans' research grant awarded by the Australian Department of Veterans Affairs, in partnership with the William Kibby VC Shed. I would like to acknowledge and thank members of the grant's project team, specifically: Melanie Takarangi, Ben Wadham, Andrew Paterson, Ella Moeck and Aidan Cornelius-Bell.

\section{References}

Adelaide Legacy. (n.d.). Our services. https://www.legacy.com.au/adelaide/OurServices. Araujo, N., Carlin, D., Clarke, B., Morieson, L., Lukas, K., \& Wilson, R. (2014). Belonging in the first year: A creative discipline cohort case study. The International Journal of the First Year in Higher Education, 5(2), 21-31. doi:10.5204/intjfyhe. v5i2.240. 
Albertson, K. (2019). Relational legacies impacting on veteran transition from military to civilian life: Trajectories of acquisition, loss, and reformulation of a sense of belonging. Illness, Crisis \& Loss, 27(4), 255-273. doi: 10.1177/1054137319834773.

Ashcroft, M.A. (2014). Veterans' transition review. http://public.ebookcentral.proquest.com/choice/publicfullrecord.aspx?p=1652911

Armstrong, J. (2012). Naturalistic inquiry. Encyclopedia of Research Design, NJ Salkind (ed.), SAGE Publications, Thousand Oaks, pp. 881-5.

Australian Catholic University. (n.d.). Student veteran support. /Study-at-acu/admission-pathways/ihave-completed-military-service/student-veteran-support

Australian National Veterans Arts Museum. (n.d.). http://anvam.org.au/

Australian Student Veterans Association: ADF to Uni. (n.d.). ASVA. https://www.asva.org.au

Bauldry, S. (2014). Conditional health-related benefits of higher education: An assessment of compensatory versus accumulative mechanisms. Social Science \& Medicine, 111, 94-100. doi: 10.1016/j.socscimed.2014.04.005.

Baumfield, V., Hall, E., \& Wall, K. (2008). Action research in the classroom. Sage Publications Ltd. doi: $10.4135 / 9780857024305$.

Bergman, B. P., Burdett, H. J., \& Greenberg, N. (2014). Service life and beyond - institution or culture? The RUSI Journal, 159(5), 60-8. doi: 10.1080/03071847.2014.969946.

Bichrest, M. M. (2013). A formal literature review of veteran acculturation in higher education. InSight: Rivier Academic Journal, 9(2).

Black, T., \& Papile, C. (2010). Making it on Civvy Street: An online survey of Canadian veterans in transition. Canadian Journal of Counselling and Psychotherapy, 44(4).

Blaikie, N.W.H. (2009). Designing social research: The logic of anticipation (2nd ed). Polity Press.

Brändle, T., \& Lengfeld, H. (2017). Drifting apart or converging? Grades among non-traditional and traditional students over the course of their studies: a case study from Germany. Higher Education, 73(2), 227-44. doi: 10.1007/s10734-016-0010-3.

Borsari, B., Yurasek, A., Miller, M.B., Murphy, J.G., McDevitt-Murphy, M.E., Martens, M.P., Darcy, M.G., \& Carey, K.B. (2017). Student service members/veterans on campus: Challenges for reintegration. American Journal of Orthopsychiatry, 87(2), 166-75. doi: 10.1037/ort0000199.

Cate, C.A. (2014). Million records projects: Research from student veterans of America. Student Veterans of America, Washington, DC.

Charles Sturt University. (n.d.). Experience matters. https://study.csu.edu.au/defence

Chester, A., Burton, L.J., Xenos, S., \& Elgar, K. (2013). Peer mentoring: Supporting successful transition for first year undergraduate psychology students. Australian Journal of Psychology, 65(1), 30-7. doi.org/10.1111/ajpy.12006.

Chesters, J., Rutter, K., Nelson, K., \& Watson, L. (2018). Alternative pathways into university: are tertiary preparation programs a viable option? Australian Universities' Review, 60(1), 35-44.

Commonwealth of Australia. (2017). The constant battle: suicide by veterans. Foreign Affairs, Defence and Trade Committee. Canberra: Senate Printing Unit, Parliament House.

https://www.aph.gov.au/Parliamentary_Business/Committees/Senate/Foreign_Affairs_Defenc e_an d_Trade/VeteranSuicide/Report

Cornelius-Bell, A., \& Bell, P. A., (2021). The academic precariat post-COVID-19. Fast Capitalism. In press. doi: 10.31235/osf.io/acu4n.

Daly, A., Lewis, P., Corliss, M., \& Heaslip, T. (2015). The private rate of return to a university degree in Australia. Australian Journal of Education, 59(1), 97-112. doi:

$10.1177 / 0004944114565117$.

Denzin, N.K., \& Lincoln, Y.S. (Eds.). (2005). The Sage handbook of qualitative research (Third ed.). Thousand Oaks, California: Sage. 
Department of Veterans' Affairs. (2017). Who is a veteran? http://clik.dva.gov.au/compensation-andsupport-policy-library/part-1-service-requirements/11- veterans/111-who-veteran

Department of Veterans' Affairs. (2017). Understanding the veteran experience. http://atease.dva.gov.au/professionals/mental-health-advice-book/part-1- understanding-veterans-andtheir-families/1-understanding-the-veteran-experience- 2/\#dvaPageSectionHeading

Egege, Y., \& Kutieleh, S. (2015). Peer mentors as a transition strategy at university: why mentoring needs to have boundaries. Australian Journal of Education, 59(3), 265-77. doi: $10.1177 / 0004944115604697$.

Flick, U. (2009). An introduction to qualitative research, (4th edition), London: Sage.

Ford, K., \& Vignare, K. (2015). The evolving military learner population: A review of the literature. Online Learning, 19(1), 7-30.

Griffith University. (n.d.). Veterans. https://www.griffith.edu.au/apply/veterans

Harvey, A., Andrewartha, L., Sharp, M., \& Wyatt-Smith, M. (2018). Supporting younger military veterans to succeed in Australian higher education. Report for the Australian Government Department of Veterans Affairs. Melbourne: Centre for Higher Education Equity and Diversity Research, La Trobe University. https://www.latrobe.edu.au/_data/assets/pdf_file/0003/933492/La-Trobe-Veterans-in-HigherEducation-Report.pdf

Hanafin, R.L. (2012). Clash of cultures. Veterans and non-veterans in academia. Military and Foreign Affairs Journal.

Jones, K. C. (2013). Understanding student veterans in transition. Qualitative Report, 18. https://eric.ed.gov/?id=EJ1043515

Kazis, L. E., Miller, D. R., Clark, J., Skinner, K., Lee, A., Rogers, W., Spiro, A., Payne, S., Fincke, G., Selim, A., \& Linzer, M. (1998). Health-related quality of life in patients served by the Department of Veterans' Affairs: Results from the veterans' health study. Archives of Internal Medicine, 158(6), 626-32. doi: 10.1001/archinte.158.6.626.

Livingston, W.G., Havice, P.A., Cawthon, T.W., \& Fleming, D.S. (2011). Coming home: Student veterans' articulation of college re-enrollment. Journal of Student Affairs Research and Practice, 48(3), 315-331. doi: 10.2202/1949-6605.6292.

Lizzio, A. (2006). Designing an orientation and transition strategy for commencing students: applying the five senses model. Griffith University: First Year Experience Project

Lizzio, A., \& Wilson, K. (2010). Strengthening commencing students' sense of purpose: Integrating theory and practice. http://www.fyhe.com.au/past_papers/papers10/content/pdf/12D.pdf

Lizzio, A., (2012). The student lifecycle: an integrative framework for guiding practice. Brisbane: Griffith University.

Mates4Mates. (n.d.). Our services. https://mates4mates.org/Get-help/Our-services

McIntyre, J., Todd, N., Huijser, H., \& Tehan, G. (2012). Building pathways to academic success. A practice reports. The International Journal of the First Year in Higher Education, 3(1), 10918. https://eprints.usq.edu.au/21194/1/McIntyre_Todd_Huijser_Tehan_PV.pdf

Meehan, C., \& Howells, K. (2019). In search of the feeling of 'belonging' in higher education: Undergraduate students transition into higher education. Journal of Further and Higher Education, 43(10), 1376-90. doi: 10.1080/0309877X.2018.1490702.

Military academic pathways. (n.d.). Flinders University. https://www.flinders.edu.au/study/pathways/military-veterans

Molina, D., \& Morse, A. (2015). Military-connected undergraduates: Exploring differences between national guard, reserve, active duty, and veterans in higher education. American Council on Education and NASPA - Student Affairs Administrators in Higher Education, Washington DC. 
https://vtechworks.lib.vt.edu/bitstream/handle/10919/97787/MilitaryUndergraduates.pdf?sequ ence $=1 \&$ isAllowed $=\mathrm{y}$

Nelson, K.J., Quinn, C., Marrington, A., \& Clarke, J.A. (2012). Good practice for enhancing the engagement and success of commencing students. Higher Education, 63(1), 83-96. doi: 10.1007/s10734-011-9426-y

On the left-Sisters in arms-Youtube. (n.d.). https://www.youtube.com/watch?v=K7SoztdOtY0

Ormston, R., Spencer, L., Barnard, M., \& Snape, D. (2014). The foundations of qualitative research. in J. Ritchie, J. Lewis, C. McNaughton Nicholls \& R. Ormston (eds.), Qualitative research practice, (2nd ed). Sage Publications, London, pp. 1-25.

Patton, M. Q., \& Patton, M. Q. (2002). Qualitative research and evaluation methods (3rd ed). Sage Publications.

Prince's Trust Australia. (2018). Defence members \& their families. https://www.princestrust.org.au/defence-members-and-their-families/

RSL DefenceCare. (n.d.). Veterans' assistance. http://www.defencecare.org.au/services/services

Schlissel, M.S., Schill, M.H., \& Drake, M.V. (2018). 3 vital ways to measure how much a university education is worth. The Conversation. http://theconversation.com/3-vital-ways-to-measurehow-much-a-university-education-is-worth-94208

Soldier On Australia. (2017). Education. https://soldieron.org.au/how-we-help/education/

Spencer, L., Ritchie, J., Ormston, R., O’Connor, W. \& Barnard, B. (2014), Analysis: Principles and processes. In J. Ritchie, J. Lewis, C. McNaughton Nicholls \& R. Ormston (eds.), Qualitative research practice (2nd ed). Sage Publications, London, pp. 243-68.

StoryRight. (n.d.). Our programs. https://www.storyright.org/our-programs/

Taniguchi, H., \& Kaufman, G. (2005). Degree completion among nontraditional college students*. Social Science Quarterly, 86(4), 912-27. doi: 10.1111/j.0038-4941.2005.00363. x.

The Productivity Commission (2019). A better way to support veterans. Productivity Commission Inquiry Report, 1(93), June, Commonwealth of Australia.

The Road Home. (n.d.). https://theroadhome.com.au/programs

Thomas, L. (2012). Building student engagement and belonging in higher education at a time of change: final report from what works? Student retention and success programme. London: HEFCE. https://www.heacademy.ac.uk/sites/default/files/resources/What_works_final_report.pdf

Tinto, V. (2009). Taking student retention seriously: rethinking the first year of university. Paper presented at the ALTC FYE Curriculum Design Symposium, Brisbane. Retrieved, http://www.yorku.ca/retentn/rdata/Takingretentionseriously.pdf

University of South Australia (n.d.). Invictus program information. https://unisa.edu.au/Businesscommunity/Community-Engagement/invictus/program-information/

Walker, R. (2012). Naturalistic research. Research Methods and Methodologies in Education, J. Arthur, M. Waring, R. Coe \& L.V. Hedges (eds), Sage Publications, pp. 76-9.

WithYouWithMe. (n.d.). Academy. https://www.withyouwithme.com/academy/academy 